\title{
Paget's disease of bone: early and late responses to three different modes of treatment with aminohydroxypropylidene bisphosphonate (APD)
}

\author{
H I J HARINCK, \\ O L M BIJVOET \\ S E PAPAPOULOS, H J BLANKSMA, A J MOOLENAAR, P VERMEIJ,
}

\begin{abstract}
Early and late responses to treatment with either oral (600 $\mathrm{mg} /$ day) or intravenous (20 $\mathrm{mg} /$ day) (3-amino-1-hydroxypropylidene)-1,1-bisphosphonate (aminohydroxypropylidene bisphosphonate; APD) were studied in 142 patients with Paget's disease of bone who had not previously been treated with bisphosphonate. The efficacy of three therapeutic regimens was compared: (a) oral aminohydroxypropylidene bisphosphonate given continuously until six months after the serum alkaline phosphatase activity had returned to normal (long term); (b) oral aminohydroxypropylidene bisphosphonate given until urinary hydroxyproline excretion had returned to normal (short term); (c) intravenous aminohydroxypropylidene bisphosphonate for 10 days. With either oral or intravenous treatment the decrease in urinary hydroxyproline excretion was rapid and always preceded the fall in serum alkaline phosphatase activity. Normal urinary hydroxyproline excretion is essential for return of the serum alkaline phosphatase activity to normal. Complete biochemical remission, defined as return of the serum alkaline phosphatase activity to normal, was obtained in 129 patients (91\%). The
\end{abstract}

Department of Endocrinology, University Hospital, Leiden, The Netherlands H I J HARINCK, MD, internist

S E PAPAPOULOS, MD, PHD, internist

A J MOOLENAAR, PHD, clinical chemist

O L M BIJVOET, MD, PHD, professor of medicine

Computer Centre, University of Leiden

H J BLANKSMA, MSC, statistician

Pharmacy, University Hospital, Leiden

P VERMEIJ, PHD, pharmacist

Correspondence and requests for reprints to: Professor O L M Bijvoet, Department of Endocrinology, University Hospital, Rijnsburgerweg 10, 2333 AA Leiden, The Netherlands. median duration of remission as assessed by actuarial analysis was $2 \cdot 7$ years.

This study found no difference in the long term among the three modes of treatment, suggesting that for most patients with Paget's disease a short course of intravenous aminohydroxypropylidene bisphosphonate will produce longlasting, complete remission without need for maintenance treatment.

\section{Introduction}

Bisphosphonates have been successfully used to treat conditions characterised by increased bone resorption. ${ }^{1}$ Among those more widely used in clinical practice, aminohydroxypropylidene bisphosphonate ((3-amino-1-hydroxypropylidene)-1, 1-bisphosphonate; APD) is very potent and has produced excellent results in Paget's disease of bone and malignant hypercalcaemia and in more rare diseases such as juvenile osteoporosis and Gaucher's disease affecting bone..$^{2-7}$

We have shown that aminohydroxypropylidene bisphosphonate predictably suppresses the activity of Paget's disease and induces long term clinical and biochemical remission. ${ }^{8}$ In this report we compare the efficacy of three different therapeutic regimens in 142 patients with active Paget's disease.

\section{Patients and methods}

Between July 1977 and July 1985, 142 out of 162 consecutive patients with Paget's disease of bone who had not previously been given bisphosphonate fulfilled the following criteria: raised serum alkaline phosphatase activity; uniform treatment with aminohydroxypropylidene bisphosphonate; and follow up for at least four months. Eighty six of the patients were men and 56 women and their ages ranged from 26 to 85 years (median 63). The diagnosis was based on scintigraphic, radiological, and biochemical criteria and in 102 cases it was confirmed histologically. ${ }^{9}$ The number of lesions per patient ranged from one to 40 , roughly half the patients having one $(n=51)$ or two $(n=29)$. In 113 cases the patients had not previously received specific treatment, and in the remaining 29 calcitonin had been stopped three 
months to three years (median 10 months) before beginning aminohydroxypropylidene bisphosphonate.

Treatment regimens-Three different treatment modalities were used: (a) $600 \mathrm{mg}$ aminohydroxypropylidene bisphosphonate by mouth daily, continued for six months after the serum alkaline phosphatase activity had returned to normal (long term treatment); (b) $600 \mathrm{mg}$ by mouth daily continued until urinary hydroxyproline excretion returned to normal (short term treatment); and (c) $20 \mathrm{mg}$ daily given by intravenous infusion for 10 days. Long term treatment as defined above was changed to short term when it was realised that serum alkaline phosphatase activity returns to normal after urinary hydroxyproline excretion; intravenous treatment was used as soon as the preparation became available. This study was therefore retrospective and, though it was not a formal randomised therapeutic trial, the patients included in each treatment modality were consecutive and unselected. Oral aminohydroxypropylidene bisphosphonate was prepared in gelatin capsules, liquid form, or enteric coated tablets and given two or three times daily half an hour before meals. The dose was chosen on the basis of findings in animals. ${ }^{10}$ Intravenous aminohydroxypropylidene bisphosphonate was infused in $500 \mathrm{ml}$ sodium chloride $0.9 \%$ over four hours, the dose being calculated from dose-response studies in patients with Paget's disease. ${ }^{8}$ Intravenous treatment was started after admission to the metabolic ward and oral treatment generally so. Patients ate a gelatin free diet adjusted to previous intake. During their hospital stay venous blood samples and measurements of body temperature (axillary) were obtained daily before breakfast. In 31 patients oral treatment was initiated in the outpatient department. Follow up was done in the outpatient department, each patient bringing two consecutive 24 hour urine collections after three days on a gelatin free diet.

Measurements-Serum alkaline phosphatase activity (normal $<60 \mathrm{U} / \mathrm{l}$ ) and calcium, phosphate, and creatinine concentrations in serum and urine were measured by an automated method. Renal tubular phosphate reabsorption capacity was calculated from a nomogram. " Urinary hydroxyproline excretion (normal 100-300 $\mu \mathrm{mol} / 24 \mathrm{~h}$ ) was measured by the method of Prockop and Udenfriend ${ }^{12}$ and expressed either as absolute values or as a percentage of the initial excess over $100 \mu \mathrm{mol} / 24 \mathrm{~h}$ (lower limit of normal).

Statistical analysis-Differences in mean values between groups were compared by Student's $t$ test (after logarithmic transformation of values in the cases of alkaline phosphatase activity and hydroxyproline excretion). Actuarial analysis of the duration of remission after completing treatment was by the method of Kaplan and Meier ${ }^{13}$ and the significance of differences in duration of remission for various groups determined by the Breslow (generalised Wilcoxon) and Mantel-Cox tests. ${ }^{14}$

\section{Results}

\section{EARLY RESPONSES}

The acute responses to either oral or intravenous aminohydroxypropylidene bisphosphonate during the first nine days refer to all 111 patients who were admitted to the metabolic ward. Seventy nine patients received oral and 32 intravenous treatment.

\section{Effects on biochemical values}

Figure 1 shows the changes in urinary hydroxyproline excretion during treatment. Values began to fall between the second and third days of treatment and continued to fall up to the ninth day. The decrease was greater with intravenous treatment, reaching a mean of $16 \%$ of the initial excess on day 9 as compared with $50 \%$ with oral treatment. The rate of fall in urinary hydroxyproline excretion was similar in each treatment group and bore no relation to initial values. Overall urinary hydroxyproline excretion decreased from a mean of 915 (SEM 211) to 267 (50) $\mu \mathrm{mol} / 24 \mathrm{~h}$ with intravenous treatment and from $730(86)$ to $475(60) \mu \mathrm{mol} / 24 \mathrm{~h}$ with oral treatment. With intravenous treatment all initial hydroxyproline excretion values below $900 \mu \mathrm{mol} / 24 \mathrm{~h}$ returned to normal, whereas the early response to oral treatment was less predictable.

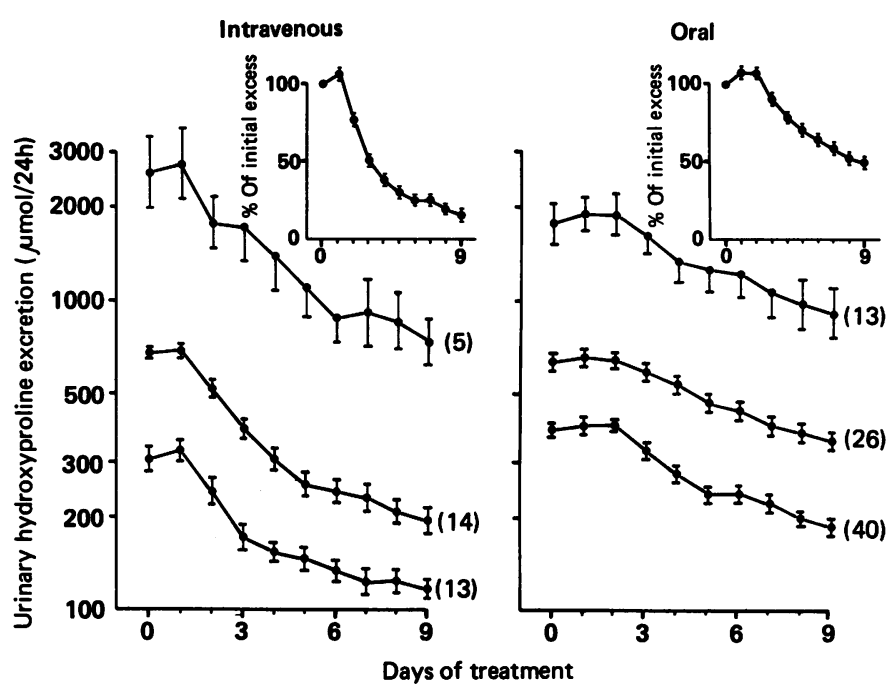

FIG 1-Sequential changes in urinary hydroxyproline excretion during first nine days of treatment with intravenous or oral aminohydroxypropylidene bisphosphonate. Patients grouped according to initial hydroxyproline excretion $(<500$, $500-1000,>1000 \mu \mathrm{mol} / 24 \mathrm{~h}$ ). Points are logarithmic means. Bars are SEM. (Numbers of patients in parentheses.)

Serum alkaline phosphatase activity also decreased during the first nine days of treatment but not as impressively as urinary hydroxyproline excretion (table I). Serum and urinary calcium concentrations significantly decreased with both oral and intravenous treatment, and this was accompanied by a significant fall in serum phosphate concentration and renal tubular phosphate reabsorption capacity (table I).

\section{Changes in body temperature}

About half the patients treated with either oral $(n=43 ; 54 \%)$ or intravenous $(n=20 ; 63 \%)$ aminohydroxypropylidene bisphosphonate had a transient increase in body temperature exceeding $0.5^{\circ} \mathrm{C}$ (fig 2). The peak increase occurred within the first $\mathbf{7 2}$ hours of treatment and was generally accompanied by mild complaints such as malaise and myalgias, which did not require analgesics. After this rise the temperature quickly decreased toward baseline.

In those patients who had a rise in body temperature a transient significant increase in urinary hydroxyproline excretion was also noted on the first day of treatment (fig 2). This was more pronounced with intravenous $(n=20 ; t=$ $2.93, \mathrm{p}<0.01)$ than with oral $(\mathrm{n}=43 ; t=2.35, \mathrm{p}<0.05)$ aminohydroxypropylidene bisphosphonate and was absent in the patients who showed no temperature rise. In the group treated intravenously this had no effect on subsequent values of urinary hydroxyproline, which decreased similarly in

TABLE I-Biochemical measurements in 111 patients with Paget's disease of bone before and after nine days of intravenous or oral treatment with aminohydroxypropylidene bisphosphonate. Values are means (SEM in parentheses)

\begin{tabular}{|c|c|c|c|c|c|}
\hline \multirow[b]{2}{*}{ Biochemical variable } & \multicolumn{2}{|c|}{ Intravenous treatment $(n=32)$} & \multicolumn{2}{|c|}{ Oral treatment $(n=79)$} & \multirow[b]{2}{*}{ Normal ranges } \\
\hline & Before & After nine days & Before & After nine days & \\
\hline $\begin{array}{l}\text { Serum alkaline phosphatase (U/l) } \\
\text { Serum calcium }(\mathrm{mmol} / \mathrm{l}) \\
\text { Serum phosphate }(\mathrm{mmol} / \mathrm{l}) \\
\text { Urinary calcium }(\mathrm{mmol} / 24 \mathrm{~h}) \\
\text { Renal tubular phosphate reabsorption capacity (mmol/l) }\end{array}$ & $\begin{array}{l}249(50) \\
2.32(0.01) \\
1.08(0.03) \\
5 \cdot 13(0.50) \\
0.94(0.04)\end{array}$ & $\begin{array}{l}183(32) \\
2 \cdot 13(0.02) \\
0 \cdot 87(0.03) \\
1 \cdot 78(0 \cdot 27) \\
0 \cdot 72(0.03)\end{array}$ & $\begin{array}{l}225(24) \\
2.36(0.01) \\
1.06(0.01) \\
4.86(0.34) \\
0.90(0.02)\end{array}$ & $\begin{array}{l}200(21) \\
2.21(0.02) \\
0.92(0.02) \\
2.33(0.24) \\
0.74(0.02)\end{array}$ & $\begin{array}{l}<60 \\
2 \cdot 20-2 \cdot 55 \\
0 \cdot 80-1 \cdot 45 \\
2 \cdot 50-7 \cdot 50 \\
0 \cdot 80-1 \cdot 30\end{array}$ \\
\hline
\end{tabular}

All differences significant $(p<0.01)$. 
patients with and without a temperature response. In the oral treatment group, however, those patients in whom no rise in temperature had occurred had a slower rate of decrease of urinary hydroxyproline; this difference was significant from day 4 onwards $(p<0 \cdot 001)$. The rise in temperature could not be predicted and was not related to the mode of administration of the drug, the dose/kg body weight, or the activity or extent of the disease.

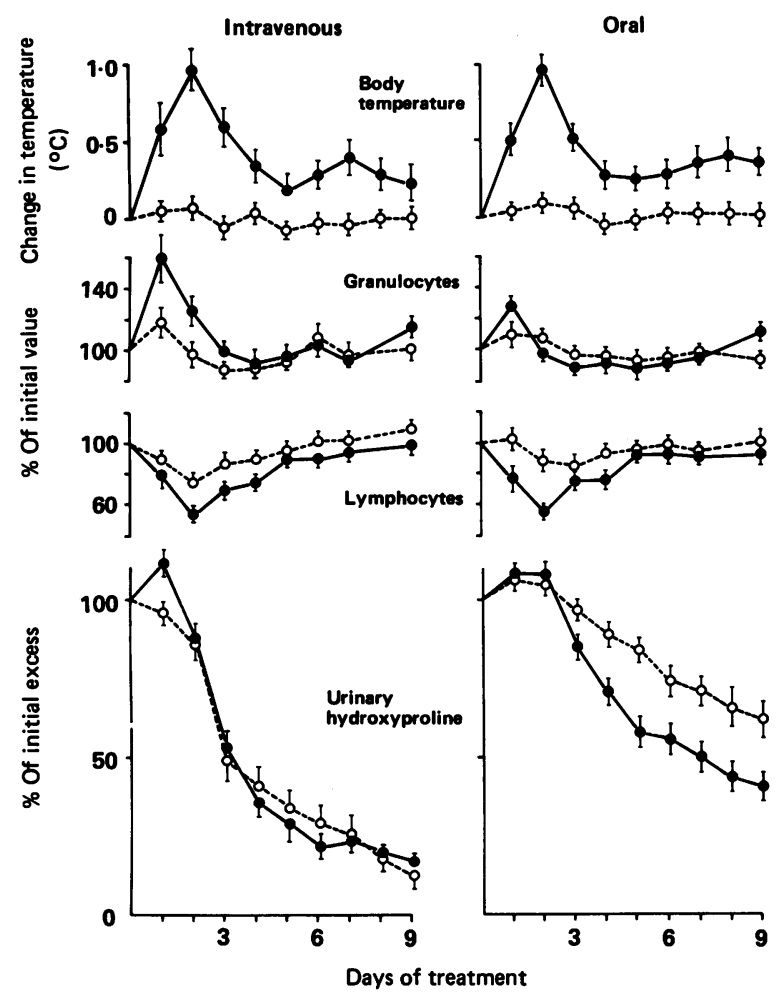

FIG 2-Changes in body temperature, white cell differential count, and urinary hydroxyproline excretion (fractional decrease of initial excess) during intravenous and oral treatment with aminohydroxypropylidene bisphosphonate. $\Theta=$ Patients with temperature rise $>0.5^{\circ} \mathrm{C}$. $\mathrm{O}=$ Patients without temperature rise. Points are means. Bars are SEM.

\section{Haematological changes}

Transient haematological changes occurred with both oral and intravenous treatment (fig 2). There was a significant increase in total white cell count with a rise in granulocytes (intravenous treatment group: $n=32, t=4.03$, $\mathrm{p}<0.001$; oral treatment group: $\mathrm{n}=79, t=3.65, \mathrm{p}<0.001$ ) and a fall in lymphocytes at 24 hours. Subsequently the white cell count began to fall and reached its lowest on day 3 . There was also a further reduction $(p<0.001)$ in the lymphocyte count to a minimum of $68 \%$ of initial values on day 2 and the appearance of band forms with no toxic granulation (maximum $30 \%$ of leucocytes on day 4). These changes corresponded with the temperature changes and reverted to baseline by the ninth day of treatment (fig 2).

\section{LATE RESPONSES}

\section{Induction of remission}

Treatment aimed at returning the serum alkaline phosphatase activity to normal, and three different modalities were used. In the first of these oral aminohydroxypropylidene bisphosphonate was continued for six months after the serum alkaline phosphatase activity had become normal ("long term" oral treatment). There were 82 patients in this group, in 76 (93\%) of whom normal serum alkaline phosphatase values were obtained between one and 15 months (median four months) after beginning treatment. The total duration of treatment ranged from six to 20 months (median 10 months). Table II shows the fall in urinary hydroxyproline excretion in these patients. Even in the six patients in whom, despite prolonged treatment (one and a half to three years), serum alkaline phosphatase activity did not reach normal levels bone turnover was reduced impressively; serum alkaline phosphatase activities decreased from 652 (SEM 98) to 90 (15) U/1 and urinary hydroxyproline excretion from 1850 (SEM 485) to 410 (117) $\mu \mathrm{mol} / 24$ hours. All these patients had extensive polyostotic disease.

In the second modality oral treatment was stopped not after return to normal of the serum alkaline phosphatase activity but after return to normal of urinary hydroxyproline excretion, which occurred two to three months earlier ("short term" oral treatment). This group had 28 patients and treatment ranged from two weeks to nine months (median one month). All these patients had a return to normal of their urinary hydroxyproline excretion, and in 25 cases (89\%) serum alkaline phosphatase activities subsequently decreased to normal (table II). The remaining three patients showed a considerable fall in serum alkaline phosphatase activity (from a mean of 186 to $70 \mathrm{U} / \mathrm{l}$ )

The third treatment modality consisted of daily infusions of $20 \mathrm{mg}$ aminohydroxypropylidene bisphosphonate for 10 consecutive days. There were 32 patients in this group, and in 27 of them urinary hydroxyproline excretion became normal by day 9 . In the other five it decreased from 3020 (SEM 928) to 860 (222) $\mu \mathrm{mol} / 24$ hours. There was no further decrease in urinary hydroxyproline excretion after the infusion was stopped. In the 27 patients in whom hydroxyproline excretion fell to normal serum alkaline phosphatase activity continued to decrease after the end of treatment and subsequently became normal in nearly all (in 26 of 27 cases in two weeks to six months, median three months). In the five patients, however, in whom urinary hydroxyproline excretion had not become normal by the end of treatment serum alkaline phosphatase activity plateaued at raised levels. Additional oral treatment with aminohydroxypropylidene bisphosphonate resulted in further reductions in serum alkaline phosphatase activity and urinary hydroxyproline excretion and return to normal values in two. These two cases are included in the assessment of overall efficacy but not in the actuarial analysis.

Figure 3 shows the individual responses of the serum alkaline phosphatase activity in all 142 patients. Values after treatment refer to those either immediately after the end of long term oral treatment or four to six months after completion of both short term treatments. In 129 cases (91\%) serum alkaline phosphatase activities had returned to normal. One year later 91 patients $(64 \%)$ still had normal serum alkaline phosphatase values. During the year 12 patients (11 with normal, one with raised serum alkaline phosphatase activities after treatment) were lost to follow up.

\section{Mode of treatment and duration of remission}

Remission begins with the induction of normal serum alkaline phosphatase activity; this occurred in 129 patients. Recurrence starts the first time that the serum alkaline phosphatase activity exceeds the upper limit of normal.

TABLE II-Early and late responses of serum alkaline phosphatase activity and urinary hydroxyproline excretion to aminohydroxypropylidene bisphosphonate. Values are means (SEM in parentheses)

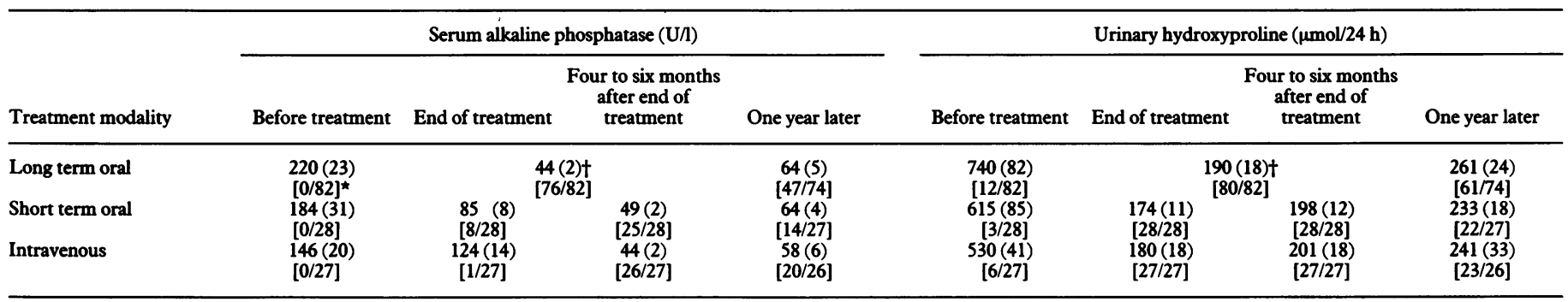

^Figures in square brackets are numbers of patients with normal values as fraction of total number. 
The median duration of remission was $2 \cdot 7$ years. There was no significant difference among the three treatment modalities in the actuarial analysis of the duration of remission (fig 4). Eleven patients were still in remission at five to eight and a half years of follow up.

Analysis of factors that may affect the duration of remission showed no significant effects for age and sex among the 129 patients. A slight effect was found for pretreatment serum alkaline phosphatase activity $(p<0.03)$ and for the number of lesions detected (patients with one lesion $(n=50)$ had longer remissions than those with more than one lesion $(n=79)(p<0.04))$. Urinary hydroxyproline concentration before or after treatment had no effect. Serum alkaline phosphatase activity after treatment, however, had a highly significant effect on the duration of remission $(\mathbf{p}<0.001)$. Thus patients with serum alkaline phosphatase activities below the median value after treatment $(n=65)$ had significantly longer remissions compared with patients with values above the median $(n=64)$. Temperature reponse or prior calcitonin treatment had no significant effect on remission.

\section{SIDE EFFECTS}

No severe side effects were noted with either oral or intravenous aminohydroxypropylidene bisphosphonate. The only problem was local irritation. With oral treatment about half the patients developed epigastric complaints, which in 13 cases necessitated temporary withdrawal of the drug. Intravenous aminohydroxypropylidene bisphosphonate may irritate the veins, and precautions must be taken by diluting the drug and infusing the total amount slowly and changing the position of the indwelling catheter at frequent intervals. Mild thrombophlebitis was noted in six patients. Blood counts and results of urine analysis and renal and liver function tests remained unaffected throughout.

\section{Discussion}

The aim of treatment in Paget's disease of bone is complete and longlasting suppression of activity of the disease without need for further treatment. This goal, which was never reached with the calcitonins, is now attainable with the second generation bisphosphonates, as we have recently shown for aminohydroxypropylidene

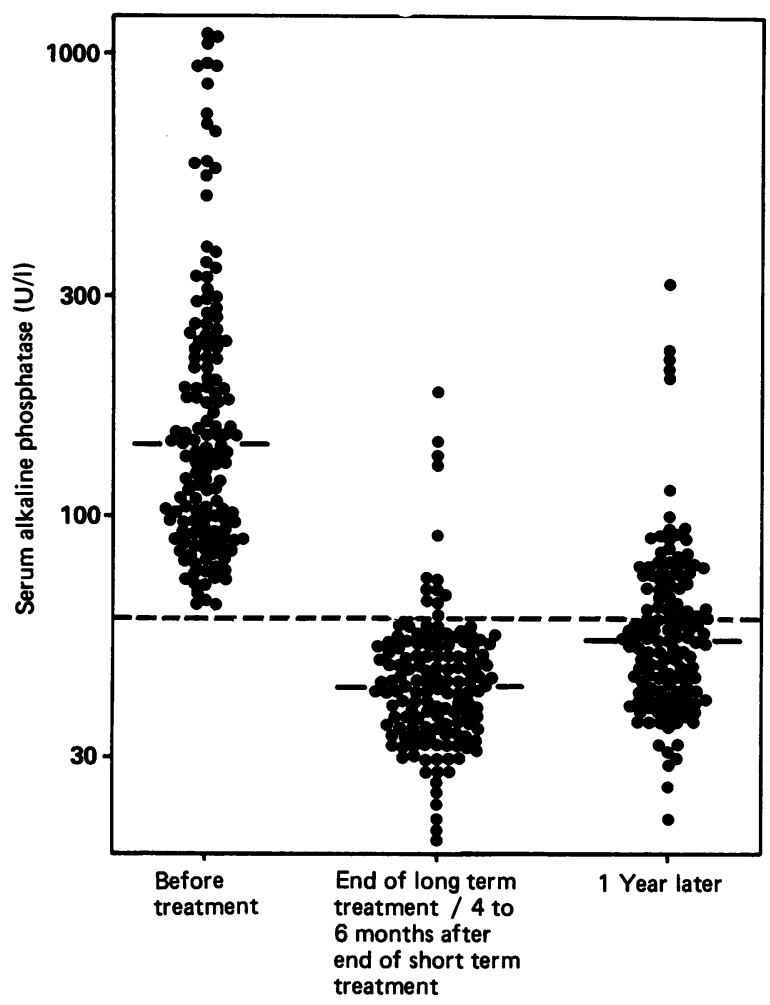

FIG 3-Serum alkaline phosphatase activities in all patients before treatment, and at end of long term treatment or four to six months after end of short term treatments (oral and intravenous), and one year later. ----=Upper limit of

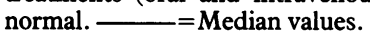

bisphosphonate in a large and representative patient population. ${ }^{8}$ In this study we have addressed the problem of treatment efficacy in relation to convenience and duration.

Our results confirm that aminohydroxypropylidene bisphosphonate is an efficacious agent for the treatment of Paget's disease, complete remission being obtained in $129(91 \%)$ of the patients in this series. Though this outcome may be achieved with long term

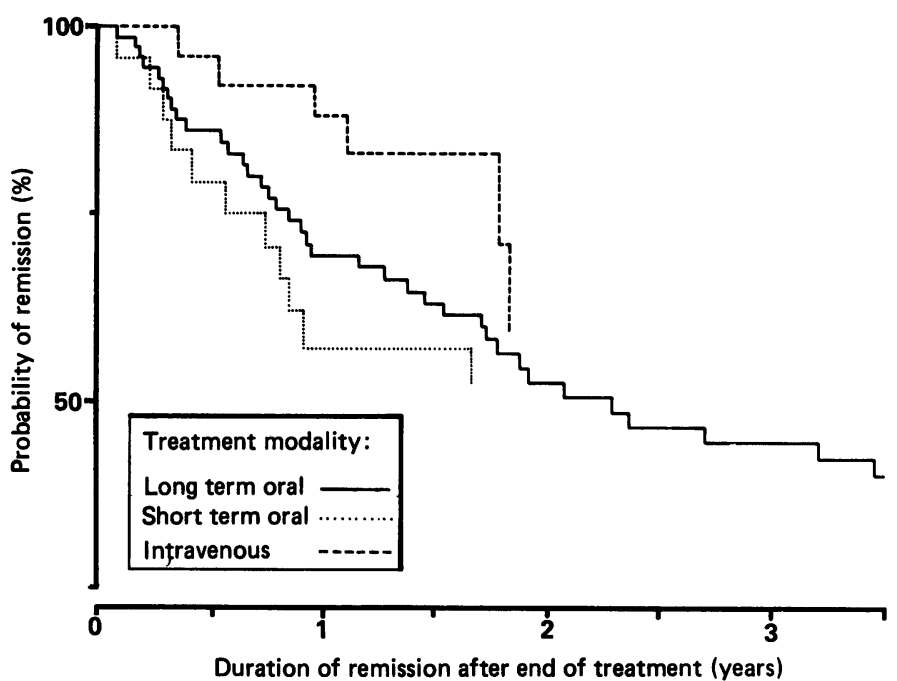

FIG 4-Actuarial analysis of durations of remission of Paget's disease of bone obtained with long term oral, short term oral, and intravenous aminohydroxypropylidene bisphosphonate. Median follow up times from normalisation of serum alkaline phosphatase activity in the three groups were: $4 \cdot 2$ years, 3.5 years, and $2 \cdot 2$ years, respectively.

oral treatment, bisphosphonates, including aminohydroxypropylidene bisphosphonate, are poorly absorbed from the intestine and the high doses required for full effect may be associated with gastrointestinal complaints. Hence it is important to explore alternative modes of delivery. This was made possible by the establishment of criteria for the efficacy of aminohydroxypropylidene bisphosphonate based on analysis of the fractional decrease of the initial excess of urinary hydroxyproline excretion in relation to the decrease in serum alkaline phosphatase values which invariably ensued. ${ }^{8}$ In this way short term regimens with either oral or intravenous aminohydroxypropylidene bisphosphonate could be tried. Our studies confirmed that in order to obtain a complete remission with return to normal of the serum alkaline phosphatase activity it was first essential to get the urinary hydroxyproline excretion back to normal. With oral aminohydroxypropylidene bisphosphonate it is not necessary to prolong treatment beyond the time at which urinary hydroxyproline excretion returns to normal. Intravenous treatment is certainly more efficacious than oral, but a 10 day course is too short to obtain remission in all patients. This is related to the kinetics of urinary hydroxyproline excretion after treatment with aminohydroxypropylidene bisphosphonate, as the rate of fall is similar for all degrees of activity and independent of initial values. Thus in patients with high activity of the disease the short intravenous course must be followed with oral aminohydroxypropylidene bisphosphonate.

Intestinal absorption of aminohydroxypropylidene bisphosphonate is about $1 \%$ of the dose and the median time required to obtain normal urinary hydroxyproline excretion with short term oral treatment is one month. Hence the amount of aminohydroxypropylidene bisphosphonate delivered with this regimen is very similar to that delivered by intravenous treatment for 10 days, suggesting that the total dose in relation to a minimal number of lesions is important for obtaining a remission. Nevertheless, the duration of remission seems to depend more on the degree of suppression of activity of the disease than on the total amount of bisphosphonate given, as insufficient, though nearly complete, sup- 
pression leads to rapid recurrence which responds to retreatment ${ }^{8}$ (unpublished observations).

The suppressive effect of aminohydroxypropylidene bisphosphonate on the activity of the disease may be long lasting, which contrasts with the experience with calcitonins: with these agents the effect is lost completely within a year. ${ }^{15}$ Direct comparisons with the other second generation bisphosphonate more commonly used in clinical practice (dichloromethylene bisphosphonate; $\mathrm{Cl}_{2} \mathrm{MDP}$ ) are not possible, mainly owing to the lack of published data on normalisation of serum alkaline phosphatase activities with its use and the clearly higher doses employed. ${ }^{16}{ }^{17}$ It should also be noted that these two bisphosphonates inhibit osteoclastic resorption by different mechanisms: aminohydroxypropylidene bisphosphonate blocks the accession of osteoclast precursors to bone, whereas dichloromethylene bisphosphonate interferes with the function of mature osteoclasts. ${ }^{18}$

In this series the rapid inhibitory effect of aminohydroxypropylidene bisphosphonate on bone resorption was shown by the fall in urinary hydroxyproline excretion and serum and urinary calcium concentrations. This was of higher magnitude with intravenous than with oral treatment but the dose delivered in the circulation with the first mode was also higher. Interestingly, during the first 24 hours of treatment with both oral and intravenous aminohydroxypropylidene bisphosphonate about half the patients had an increase in urinary hydroxyproline excretion. These were the patients who also showed transient temperature rises and haematological changes. We have previously shown these transient changes in a small group of patients treated with oral aminohydroxypropylidene bisphosphonate,$^{19}$ and they have also been reported with other aminobisphosphonates. ${ }^{20}$ The occurrence of these changes in the same proportion of patients whether treated by mouth or intravenously shows clearly that they are not related to differences in absorption with the oral preparations and suggests a direct or indirect effect of this bisphosphonate on the mononuclear phagocyte system, possibly through release of lymphokines or cytokinins. We know, for example, that interleukin 1 may increase bone resorption in vitro and may also induce haematological changes similar to those noted in this study. ${ }^{21} 22$ Such changes, however, are never seen in patients who have previously received aminohydroxypropylidene bisphosphonate (unpublished observations), and the early decrease of urinary hydroxyproline is much less in patients with no temperature rise. Possibly, therefore, these transient phenomena are related to the mechanism of action of aminohydroxypropylidene bisphosphonate. We have shown that aminohydroxypropylidene bisphosphonate has no direct effect on osteoclast precursors, which share the same origin with the macrophage system, but that its action on the bone matrix alters its ability to induce transformation of precursor into mature osteoclasts. ${ }^{1823}$ This suggests that the induction of this transient response is due to an indirect action of aminohydroxypropylidene bisphosphonate on osteoclast precursors through a mechanism entailing recognition of bone matrix by the bisphosphonate. This, however, warrants further investigation.

The side effects of aminohydroxypropylidene bisphosphonate are due to local irritation, which may be particularly troublesome with the oral preparations. The effect is dose related and very rarely seen in patients given $300 \mathrm{mg} /$ day or less. Conversely, daily doses higher than $600 \mathrm{mg}$ are poorly tolerated by most patients.

Treatment of Paget's disease of bone must aim at maximal suppression of serum alkaline phosphatase values to within the normal range. This can best be achieved by short term intravenous aminohydroxypropylidene bisphosphonate in most patients. If the activity of the disease is high this regimen must be supplemented with oral aminohydroxypropylidene bisphosphonate at a dose which does not cause gastric irritation. In this way complete and longlasting remissions can be obtained.

We thank all the physicians who referred their patients to us. We are grateful to the nurses of the clinical investigation unit for their help, Dr J H M Souverijn of CKCL for the biochemical measurements, Mrs $M$ van Wijk-van Lennep for expert technical work, and Mrs R de Graaf for typing the manuscript. The aminohydroxypropylidene bisphosphonate used in these studies was a gift from Henkel KGaA, Düsseldorf, Federal Republic of Germany.

\section{References}

1 Fleisch H. Bisphosphonates: mechanism of action and clinical applications. In: Peck WA, ed. Bone and mineral research. Annual 1. Amsterdam: Excerpta Medica, 1983:319-57.

2 Frijlinck WB, te Velde J, Bijvoet OLM, Heynen G. Treatment of Paget's disease of bone with (3-amino-1-hydroxypropylidene)-1,1-bisphosphonate (APD). Lancet 1979;i:799-803.

3 Sleeboom HP, Bijvoet OLM, Van Oosterom AT, Gleed JH, O'Riordan JLH. Comparison of intravenous (3-amino-1-hydroxypropylidene)-1,1-bisphosphonate and volume repletion in tumour-induced hypercalcaemia. Lancet 1983;i:239-43.

4 Thieband D, Jeager P, Jacquet AF, Burckhardt P. A single-day treatment of tumour-induced hypercalcaemia by intravenous amino-hydroxypropylidene bisphosphonate. Joumal of Bone and Mineral Research 1986;1:555-62.

5 Harinck HIJ, Bijvoet OLM, Plantingh AST, et al. The role of bone and kidney in tumor-hypercalcemia and its treatment with bisphosphonate and sodium chloride. Am $\mathcal{f}$ Med tumor-hypercalcemis

6 Hoekman K, Papapoulos SE, Peters ACB, Bijvoet OLM. Characteristics and bisphosphonate treatment of a patient with juvenile osteoporosis. F Clin Endocrinol Metab 1985;61:952-6.

7 Harinck HIJ, Bijvoet OLM, Van der Meer JWH, Jones B, Onvlee GJ. Regression of bone lesions in Gaucher's disease during treatment with amino-hydroxypropylidene bisphosphonate. Lancet 1984;i:513.

8 Harinck HIJ, Bijvoet OLM, Blanksma HJ, Dallinghaus-Nienhuys PJ. Efficacious managemen with amino-bisphosphonate (APD) in Paget's disease of bone. Clin Orthop 1987;217:79-98.

9 Harinck HIJ, Bijvoet OLM, Vellenga CJLR, Blanksma HJ, Frijlink WB. Relation between signs and symptoms in Paget's disease of bone. Qf Med 1986;58:133-51.

10 Reitsma PH, Bijoet OLM, Verlinden-Ooms H, v d Wee-Pals LJA. Kinetic studies of bone and mineral metabolism during treatment with (3-amino-1-hydroxypropylidene)-1,1-bisphosphonate (APD) in rats. Calcif Tissue Int 1980;32:145-57.

11 Bijoet OLM. Measurement of renal handling of phosphate. In: Massry SG, Fleisch H, eds. Renal handling of phosphate. New York and London: Plenum, 1980:1-37.

12 Prockop DJ, Udenfriend S. A specific method for the analysis of hydroxyproline in tissues and urine. Anal Biochem 1960;1:228-39.

13 Kaplan EL, Meier P. Non-parametric estimation from incomplete observations. Foumal of the American Statistical Association 1958;53:457-81.

14 Kalbfleisch JD, Prentice RL. The statistical analysis of failure time data. New York: Wiley, 1980.

15 MacIntyre I, Evans NA, Hobitz HHG, Joplin GF, Stevenson JC. Chemistry, physiology and therapeutic applications of calcitonin. Arthritis Rheum 1980;23:1139-54.

16 Delmas PD, Chapuy MC, Vignon E, et al. Long-term effects of dichloromethylene diphosphonate in Paget's disease of bone. $\mathcal{F}$ Clin Endocrinol Metab 1982;54:837-44.

17 Yates AJP, Gray RES, Urwin GH, et al. Intravenous chlodronate in the treatment and retreatment of Paget's disease of bone. Lancet 1985;i:1474-7.

18 Boonekamp PN, v d Wee-Pals LJA, v Wijk-v Lennep MML, Thesingh CW, Bijvoet OLM. Two modes of action of bisphosphonates on osteoclastic resorption of mineralized matrix. Bone and Mineral 1986;1:27-39.

19 Bijvoet OLM, Vrijlink WB, Jie K, et al. APD in Paget's disease of bone. Role of the mononuclear phagocyte system? Arthritis Rheum 1980;23:1193-204.

20 Adami S, Salvagno G, Guarrera G, et al. Treatment of Paget's disease of bone with intravenous 4-amino-1-hydroxybutylidene-1,1-bisphosphonate. Calcif Tissue Int 1986;39:226-9.

21 Gowen M, Mundy GR. Actions of recombinant interleukin-1, interleukin-2 and interferon on bone resorption in vitro. $\mathcal{f}$ Immunol 1986;136:2478-82.

22 Dinarello CA. Interleukin-1 and the pathogenesis of the acute-phase response. $N$ Engl $\mathcal{F}$ Med 1984;311:1413-8.

23 Boonekamp PM, Löwik CWGM, v d Wee-Pals LJA, v Wijk-v Lennep MLL, Bijvoet OLM. Enhancement of the inhibitory action of APD on the transformation of osteoclast precursors into resorbing cells after dimethylation of the amino group. Bone and Mineral 1987;2:29-42.

(Accepted 25 August 1987)

\section{YEARS AGO}

The police at Birkenhead appear to take a more comprehensive view of their duties than they do in other places, notably in London. Last week the magistrate was called upon to settle a point which is certainly not devoid of interest for the inhabitants of towns; namely, as to the way in which workmen are at liberty to carry their tools through the street when walking on the footpath. In this particular case a coalheaver was summoned for carrying a spade with the blade projecting over his shoulder. The case was dismissed as the magistrate was not satisfied that the public had really been exposed to risk of injury. It is quite possible that in this instance the prosecution was not well advised, but the question merits attention. The careless way in which workmen carry pointed, cutting or other dangerous tools along public thoroughfares is by no means rarely the cause of accidental wounds. A carpenter who carries a saw, projecting out of the bag slung over his back, has been the involuntary cause of a serious scalp wound to a passerby, and injuries resulting from collision with planks, iron bars, and so forth, are of extremely common occurrence. Not long since, a workman in Paris took with him on the tramcar a keg of sulphuric acid, which he managed to break, inflicting terrible injuries on himself, his fellow passengers, and the horses. A man has no more right to carry a tool to the common danger, than he has to twirl his stick or umbrella round at the risk of abrading or removing an eye or upper lip. (British Medical fournal 1887;i:894.) 